\title{
Strategy \& Techniques for Restoration of Healthy Aquaecosystem from Toxic Super Eutrophic Water Body
}

\author{
Peimin Pu${ }^{1}$, Jiangping $\mathrm{Pu}^{2}$ \\ ${ }^{1}$ Nanjing Institute of Geography \& Limnology, Academia Sinica, Nanjing, China \\ ${ }^{2}$ PLA University of Science and Technology, Nanjing, China \\ Email: pupm2@qq.com, pupm1@yahoo.com
}

Received 5 July 2015; accepted 20 August 2015; published 25 August 2015

\section{Abstract}

There are complex river-lake systems in the Taihu Lake catchment with total water surface area of $6174.7 \mathrm{~km}^{2}$, and population density of $1079 / \mathrm{km}^{2}$, including Taihu Lake water surface area of 2338 $\mathbf{k m}^{2}$. The water systems in this catchment have healthy aquaecosystems during long history. However, in some riverlets in this catchment the water quality was estimated as "acute toxicity for higher organisms" and over standards for many heavy metal elements content; there were no any living plants and macro organisms in the water body, because there were developed a series of industry with abundant release of heavy metals and difficult decomposition organic chemical components along the riverlets during last decades. The even more serious situation was observed in sediments of the riverlets. How to restore such riverlet into a healthy aquaeosystem with abound plants and higher organisms? The main strategy and techniques are described in this paper as summarizing a report of engineering in a riverlet in Wuxi New District during last years, which leads to restore the aquaecosystem into a healthy one with abundant surface plant cultured on floating islands and observed living fish, lobster, frog, toad, mollusk and others in the riverlet. The main techniques are: 1) softwall buffer technic; 2) floating eco-island technic by using which can culture any plant which can be cultured in solution; 3 ) immobilized nitrogen cycle bacteria (INCB) technic; 4) tattering esters and other big-molecule organic chemicals by using electronic pulse technic and photosensitization technic; 5) mist spray facility technic for improving dissolved oxygen in deep water layers; 6) technic for buffering and suppressing $\mathrm{H}_{2} \mathrm{~S}$ release from water; 7) the appropriate portion of surface with cultured plant to the total water surface area is about $1 / 3$; 8) Cress [Oenanthe Ljavanica (BI.) DC.] and Myriophyllum verticilatum L. may be cultured in Taihu Lake catchment during the whole year as main plants with mosaic combination of other supplement plants in different seasons.

\section{Keywords}

Restoration of Healthy Aquaecosystem, Toxic Water Body, Electronic Pulse Technique for Decomposition Esters, Photosensitization for Decomposition of Organic Matters, Floating Eco-Islands, Immobilized Nitrogen Cycle Bacteria 


\section{Introduction}

Taihu Lake has water surface of $2338 \mathrm{~km}^{2}$. There are complex river-lake systems in its catchment with total water surface area of $6174.7 \mathrm{~km}^{2}$, and population density of $1079 / \mathrm{km}^{2}$. The water systems in this catchment have healthy aquaecosystems during long history. The river-lake systems were used as the easiest way for storing all the industrial, agricultural, and domestic wastewater. The pollution loading was exceeded usually the purification capacity of the water body. Therefore, the water quality in the riverlet becomes worse and worse at the densely populated and economic developed zone, spot by spot. The aquaecosystems in the riverlet deteriorate and the purification capacity decreases gradually. The vicious cycle of aquaecosystem deterioration happened during last decades. The water plants disappear gradually. Many pollutants store at the bottom and usually release detrimental solid, dissolved liquid, and gaseous (such as toxic $\mathrm{H}_{2} \mathrm{~S}$ ) substances. As an example, there is a riverlet in Wuxi New District, in which there were no any living plants and macro organisms in the water body, because there were densely populated and developed a series of industry with abundant release of heavy metals and difficult decomposition organic chemical components along the riverlets during last decades. The even more serious situation was observed in sediments of the riverlets.

How to restore such riverlet into a healthy aquaeosystem with abound plants and higher organisms? The usual approaches for restoring eutrophic/hyper-eutrophic water system could not be used in such case, because of macrophyte could not live in such a water body. The new strategy and techniques should be developed. For this purpose, a demonstrative project has been performing since 2011. The main results are summarized in this paper.

\section{Background Information}

\subsection{Geographic and Hydrological Situation}

The riverlet segment of the project is located in Wuxi New District in East-West direction in Taihu Lake catchment, belonging to the Wangyuhe river system. It has width of $12-20 \mathrm{~m}$ and length of $1000 \mathrm{~m}$. The across section has $U$ shape with steep coasts and $3.5 \mathrm{~m}$ deepest bottom under normal water level. The hydrological conditions are related with the surroundings and rainfall. The maximun amplitude of water level reaches round by $1 \mathrm{~m}$ during heavy rainfall (it was $1.5 \mathrm{~m}$ during last rainfall 16 - 17 June 2015, while all the facilities of project were safety). The current direction is changeable with maximum speed of over $15 \mathrm{~cm} / \mathrm{s}$. The bottom was dredged several years ago.

This riverlet had a healthy aquaecosystem with very good water quality and dense macrophyte population a couple decades ago. But the water quality becomes worse and worse in relation with rapid development of a series of industry with abundant release of heavy metals and difficult decomposition organic chemical components and rapid population growth along the riverlet during last decades. Macrophyte in the riverlet disappeared gradually in recent years.

\subsection{Water Quality State in the Beginning of the Project}

The water colour was dark black with frequent release of bad smell of $\mathrm{H}_{2} \mathrm{~S}$, should work there with gas mask. The water surface was covered with oil and esters frequently, especially when the bubbles appeared on the surface. The $\mathrm{COD}_{\mathrm{Cr}}$, TP, TN was measured as 372 - $8770 \mathrm{mg} / \mathrm{L}, 4.74$ - $13.20 \mathrm{mg} / \mathrm{L}$, and 34.0 - $55.6 \mathrm{mg} / \mathrm{L}$ separately at 6 sites along the reverlet on 1 November 2012. In the dense area of esters The COD $_{\mathrm{Cr}}$ reached 14,911 28,448 mg/L on August 2011.

The detected data by ICP-MS show the concentration of $\mathrm{Al}, \mathrm{Mn}, \mathrm{Fe}, \mathrm{Ni}, \mathrm{Pb}$ is exceed the national standards, especially the $\mathrm{Al}$ concentration is 5 - 19 times more than national standard.

The biological acute toxicity of the water samples was determined by standard method of GB/T15441-1995 and was estimated according to the American State Standard as "acute toxicity for higher organisms".

\section{Technical Approaches}

\subsection{Scheme of the Technical Approaches}

The high polluted water has non-uniform pattern usually, as water masses with different characteristics. We should take different approaches for different water masses, which are listed in the scheme as follows: 


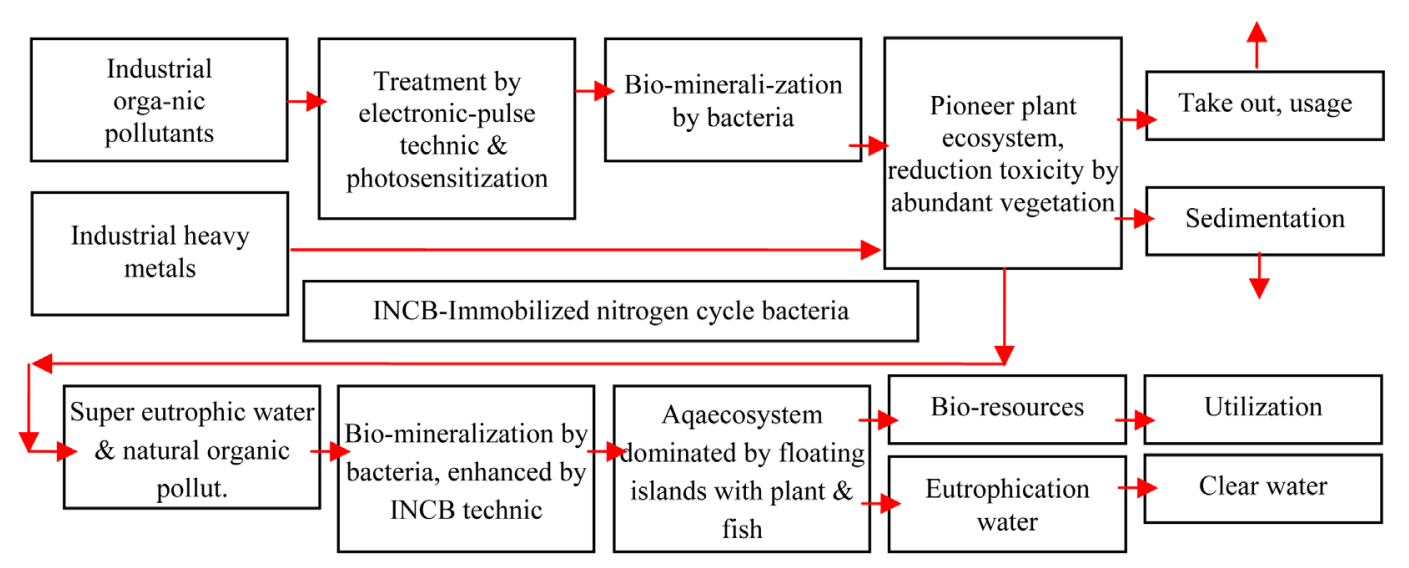

\subsection{Main strategy and technics}

The main strategy and technics are:

1) Limit the high concentration pollutants at the sites of their release in as small area as possible, and protec the better ecosystems, decreasing the negative influences of worse water mass, controlling the exchange rate between the masses, by using softwall technic [1]-[3];

2) Take different treatment technics for different water masses;

3) Take complex enhanced measures, so the threshold would be exceeded for restoring healthy ecosystem and improving water quality in a limited area;

4) The horizontal non-uniform distribution method could be used for improving vertical exchange of water characteristics. For example, the water temperature in the open place is higher than that under the floating eco-islands during sun shine day, the non-uniform horizontal water temperature will generate the vertical exchange currents, and oppositely, the water temperature in the open place is lower than that under the floating eco-islands during night, the vertical exchange movement will occur in opposite direction;

5) The mosaic distribution of plants benefits for preventing plant diseases and insect pests and absorbing nutrients in balance for ecosystem stable during season's exchange;

6) Because of the industrial organic matters could not be easy destroyed by bacteria, so, the industrial organic pollutants should be removed by management and destroyed into organic matters easy be biomineralized by bacteria, by using electronic-pulse technic and photosensitization, then; the nutrients be absorbed by plants partly, cultured on the floating islands [4], reducing the toxicity of water quality; and in this case the water quality would be the similar one of the super eutrophic water;

7) The super eutrophic water would be bio-mineralized by bacteria, enhanced by immobilized nitrogen cycle bacteria (INCB) technic [5] [6];

8) Construction of aquaecosystem dominated by floating islands technic with plant and total planting area of about $1 / 3$ to the total water area as the optimized ratio;

9) The oxygenation technic and technic for removing hydrogen sulfide $\left(\mathrm{H}_{2} \mathrm{~S}\right)$ in water should be used in case, if necessary.

\subsection{Details for Some Technics}

1) Electronic-pulse technic for tattering esters and other big-molecule organic chemicals. The electric voltage of 24 VDC in the riverlet was used for safety in the riverlet. The special frequency, intensity of the pulse, ratio of pulse width/interval and electrode substances (especially the substance for anode) should be well tested and chose. The esters become more diluted and easier to be further decomposed after a few hours treatment.

2) Photosensitization technic for absorb esters and oil by using plant, which could died after attaching oil and transformed into humus. The humus may intensively absorb the photo energy with wave length less than $500 \mathrm{~nm}$, part absorbed energy of that would be transported to the artificial synthesis substances and acting as the decomposition factors. The esters and oil round the dead plant disappear gradually. The organic matters decomposed by bacteria and should be absorbed by other living plant gradually.

3) There are no submerged plants, so the dissolved oxygen is transported from the air-water interface. The 
oxygen consumption process in water, especially in lower layer of the riverlet leads to oxygen deficit in lower water. Oxygenation by air pump in deep layer needs to overcome the water pressure and to create as small as possible air bubbles. A fact had been revealed that the dissolved oxygen in the water collected from water-drops after mist spray of water from very low saturation level of dissolved oxygen (such as $\leq 0.2 \mathrm{mg} / \mathrm{L}$ ) has oversaturation of $108 \%$. This kind of oversaturated water can be collected in the bucket floating on the water surface with a water level in it higher than that of the water level in the river/reservoir. Then the water in the bucket with high dissolved oxygen can be lead to the deep layers in the river/reservoir by a tube, using the effect of syphonage.

4) Controlling of hydrogen sulfide $\left(\mathrm{H}_{2} \mathrm{~S}\right)$ : There are so many esters and other organic pollutants stored in bottom of the riverlet, which would release toxic $\mathrm{H}_{2} \mathrm{~S}$ during anaerobic decomposition process. If we use $\mathrm{Fe}_{2} \mathrm{O}_{3} \cdot \mathrm{H}_{2} \mathrm{O}$ during oxygenation, the $\mathrm{H}_{2} \mathrm{~S}$ may be transformed into $\mathrm{Fe}_{2} \mathrm{~S}_{3}$ and $\mathrm{FeS}$ as follows:

$\mathrm{Fe}_{2} \mathrm{O}_{3} \cdot \mathrm{H}_{2} \mathrm{O}+3 \mathrm{H}_{2} \mathrm{~S} \rightarrow \mathrm{Fe}_{2} \mathrm{~S}_{3} \cdot \mathrm{H}_{2} \mathrm{O}+3 \mathrm{H}_{2} \mathrm{O} \Delta \mathrm{H}=63 \mathrm{KJ} / \mathrm{mol} ; \mathrm{Fe}_{2} \mathrm{O}_{3} \cdot \mathrm{H}_{2} \mathrm{O}+3 \mathrm{H}_{2} \mathrm{~S} \rightarrow 2 \mathrm{FeS}+\mathrm{S}+4 \mathrm{H}_{2} \mathrm{O} \Delta \mathrm{H}=103$ $\mathrm{KJ} / \mathrm{mol}$.

We may use the industrial desulfurizer to absorb the $\mathrm{H}_{2} \mathrm{~S}$, if it appears as follows:

$2 \mathrm{Fe}(\mathrm{OH})_{3} \cdot \mathrm{xH}_{2} \mathrm{O}+3 \mathrm{H}_{2} \mathrm{~S} \rightarrow \mathrm{Fe}_{2} \mathrm{~S}_{3} \cdot \mathrm{xH}_{2} \mathrm{O}+6 \mathrm{H}_{2} \mathrm{O}$ (desulfurization)

$\mathrm{Fe}_{2} \mathrm{O}_{3} \cdot \mathrm{xH}_{2} \mathrm{O}+3 \mathrm{H}_{2} \mathrm{~S}=\mathrm{Fe}_{2} \mathrm{~S}_{3} \cdot \mathrm{xH}_{2} \mathrm{O}+3 \mathrm{H}_{2} \mathrm{O}$ (desulfurization); $\mathrm{Fe}_{2} \mathrm{~S}_{3}=2 \mathrm{FeS}+\mathrm{S}$ (decompozation), and to regenerate it when the dissolved oxygen is enough, or take it into air condition:

$\mathrm{Fe}_{2} \mathrm{O}_{3} \cdot \mathrm{xH}_{2} \mathrm{O}+\mathrm{O}_{2}=\mathrm{Fe}_{2} \mathrm{~S}_{3} \cdot \mathrm{xH}_{2} \mathrm{O}+3 \mathrm{~S}$ (regeneration); $2 \mathrm{FeS}+\mathrm{O}_{2}+\mathrm{xH}_{2} \mathrm{O}=\mathrm{Fe}_{2} \mathrm{O}_{3} \cdot \mathrm{xH}_{2} \mathrm{O}+2 \mathrm{~S}$ (regeneration)

For this purpose, we may set the industrial desulfurizer in the net tubelets, which are fixed on the industrial textile for setting on the submerged islands (Figure 1(a)). All these facilities function as buffering and suppressing $\mathrm{H}_{2} \mathrm{~S}$ release from water. The desulfurizer becomes black colour after absorbing $\mathrm{H}_{2} \mathrm{~S}$ (Figure 1(b)), and returns to brown colour after regeneration in air/or in water with high dissolved oxygen concentration (Figure 1(c)).

5) Distribution of islands for culturing plants: A synthetic fibre rope net can be constructed according to the riverlet shape at site for fixing the islands. The floating eco-islands ( $2 \mathrm{~m}^{* 4 \mathrm{~m}}$ ) [4] [6] occupy the surface area with appropriate ratio about $1 / 3$ to the total water surface. The other $2 / 3$ surface may be occupied by submerged islands in case necessary for restoration submerged macrophyte (coloured by blue rectangles). The distribution scheme of the islands is shown in Figure 2.

6) Mosaic culture of plants: Cress [Oenanthe Ljavanica (Bl.) DC.] and Myriophyllum verticilatum L. may be cultured in Taihu Lake catchment during the whole year as main plants with mosaic combination of other supplement plants in different seasons. The toxic super eutrophic riverlet had been restored to a healthy aquaecosystem with abundant surface plant cultured on floating islands and observed living fish, lobster, frog, toad, mollusk and others in it-a healthy aquaecosystem (Figure 3).

\section{Purification Effects of the Aquaecosystem Dominant by Surface Plant}

The purification effects of the aquaecosystem dominant by surface plant may be summarized in Figure 4.

The density of heavy metal decreased above a couple of times to maximum of 25 - 43 times (Figure 4(a)). For example, the cress may increase DO with mean value of $0.63 \mathrm{mg} / \mathrm{L}$, or $74.7 \%$ during 20150402-20150519, and occasionally up to $2.5 \mathrm{mg} / \mathrm{L}$. The TDS (total dissolved solid) can be used as an indicator of density of nutritive salts-pollutants. In certain period the high density pollution was loaded (Figure 4(c), red ellipsoid) with maximum

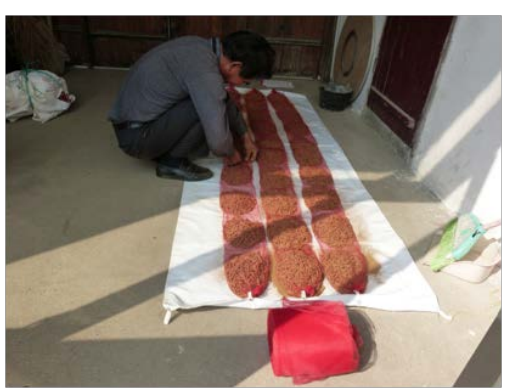

(a)

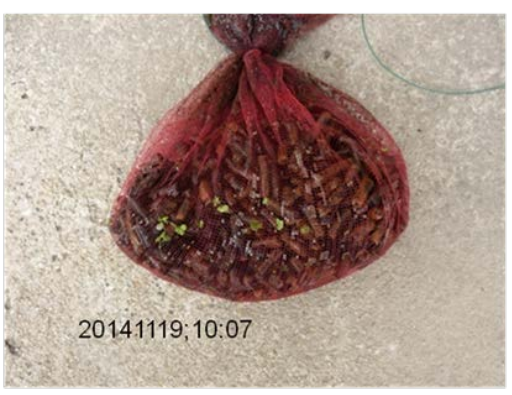

(b)

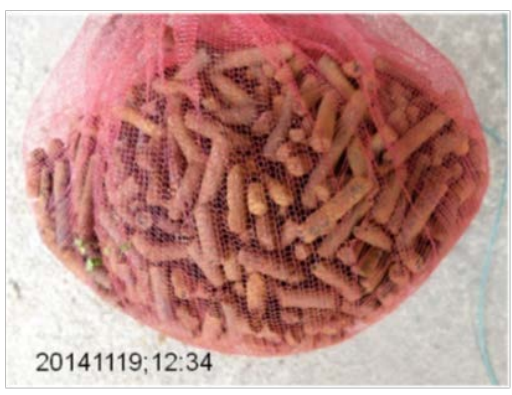

(c)

Figure 1. Setiing the industrial desulfurizer in the net tubelets, which are fixed on the industrial textile for setting on the submerged islands (a), desulfurization in water with $\mathrm{H}_{2} \mathrm{~S}$ (b), and regenerization after $2^{\mathrm{h}} 27^{\mathrm{m}}$ in air (c). 


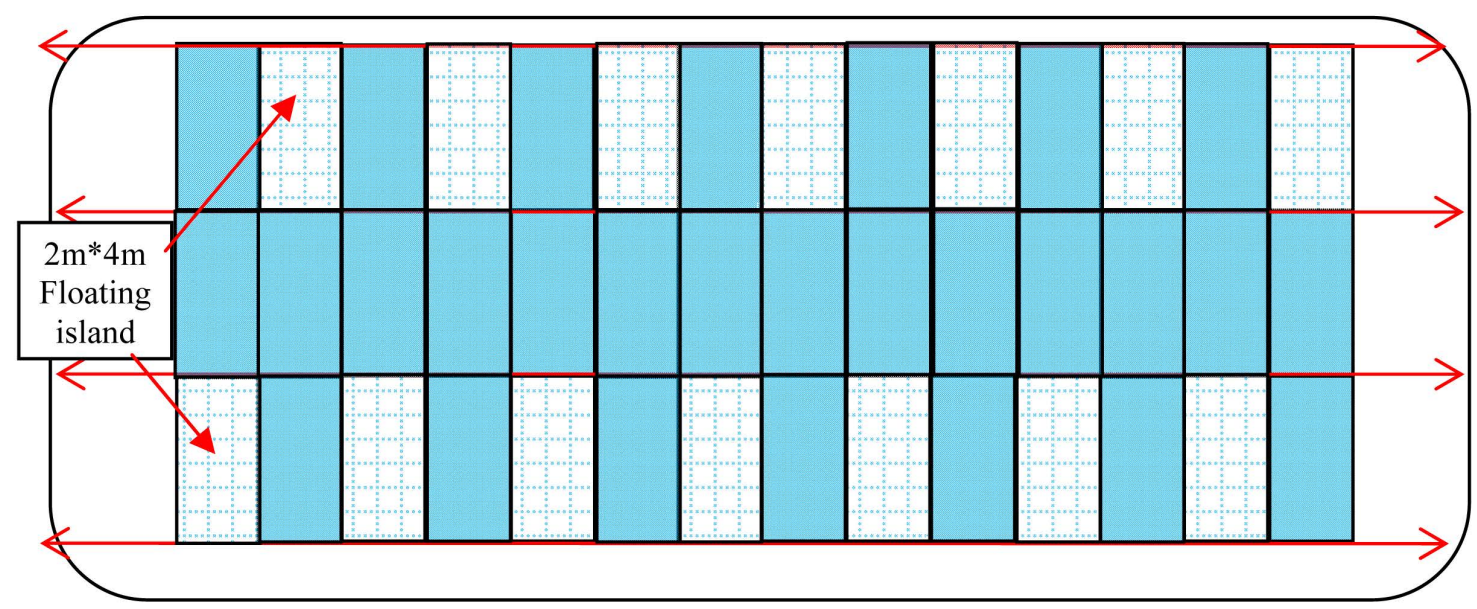

Figure 2. Scheme for distribution of floating eco-islands $(2 \mathrm{~m} * 4 \mathrm{~m})$, occupying the surface area with appropriate ratio about $1 / 3$ to the total water surface. The other $2 / 3$ surface may be occupied by submerged islands in case necessary for restoration submerged macro-phyte (coloured by blue rectangles).
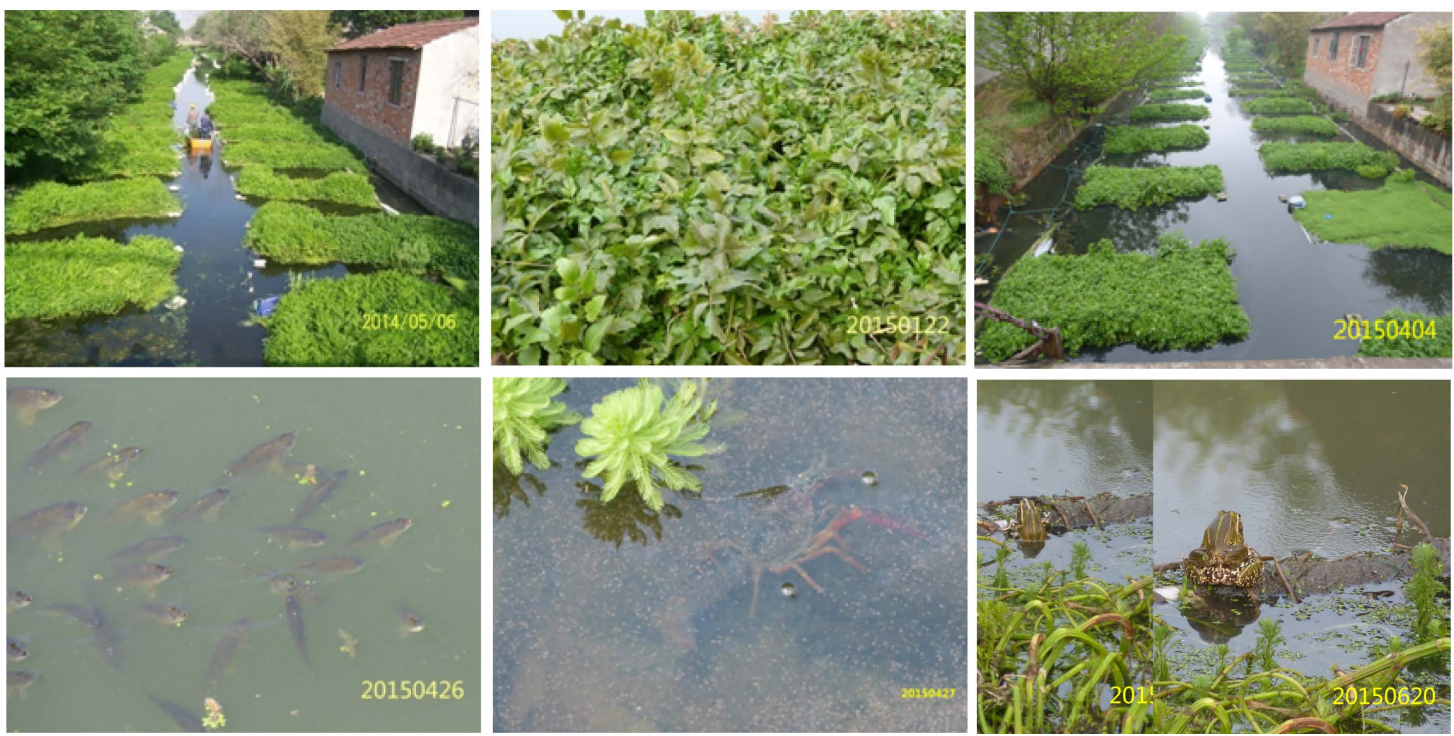

Figure 3. Abundant surface plant cultured on floating islands and observed living fish, lobster, frog, toad, mollusk and others in it—a healthy aquaecosystem.

of TDS $=897 \mathrm{mg} / \mathrm{L}$ (average along the riverlet on 20141227). It was $252 \mathrm{mg} / \mathrm{L}$ (average along the riverlet on 20150516), decreased on 3.6 times. The square of correlation coefficient between TDS under plant and in adjacent riverlet was 0.939 (Figure 4(d)). There are reports showing that the cress may remove TP $74.8 \%$ and its root may release oxygen and other wetland plants have similar function: releasing oxygen and absorbing nutrients and heavy metals [7]-[9].

The monitoring data on $\mathrm{COD}_{\mathrm{Cr}}, \mathrm{COD}_{\mathrm{Mn}}, \mathrm{TP}, \mathrm{TN}, \mathrm{NH}_{4}^{+}$, etc. showed that they were high/very high at the pollution loading entrances into the riverlet and were as low as standards for landscape reuse water. It seems we have had constructed a sewage plant. It needs about $¥ 10^{7}$ for construction and $¥ 1650 / d$ for daily management, as the population in this area is about 10,000, according to the data for adjacent Meicun sewage plant [10]. This is much more expensive than that for performing this restoration aquaecosystem project and its maintenance. As there are abundant cress and other vegetation on floating eco-island, which purify the water and contain nutrition and less concentration density of heavy metals, leading to decrement of toxity, and therefor, can be used as the natural resources. There are about $3837 \mathrm{~km}^{2}$ riverlets-small lakes in Taihu Lake catchment. If we can use a part of these water surface, we may organize and develop an agricultural-environmental industry. 

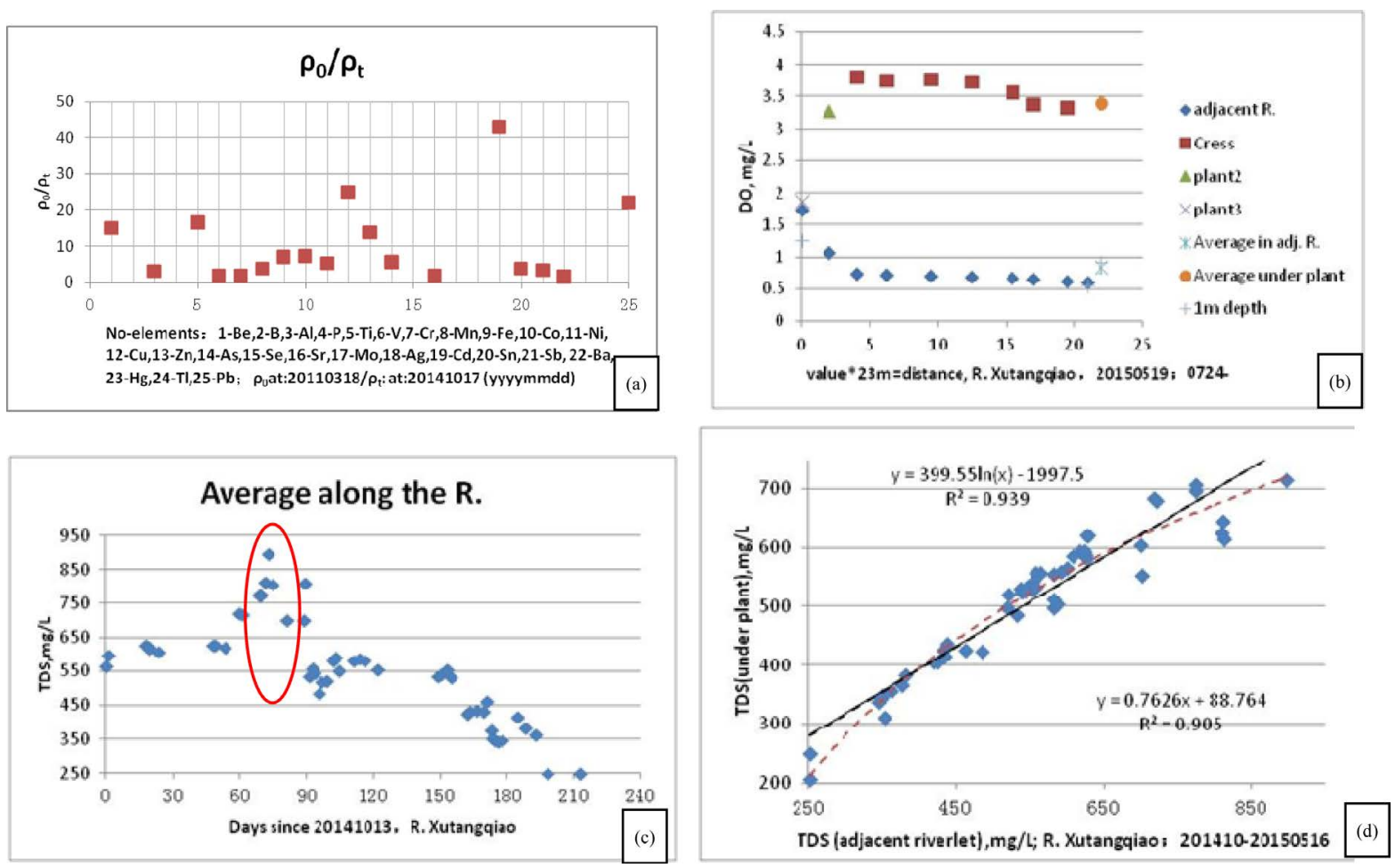

Figure 4. Improvement of water quality in ratio of original density of heavy metal $\rho_{0}$ to recent $\rho_{t}$ (a); Dissolved oxygen under plants and in adjacent R. (b); Variation of average TDS along the R. (c); Relationship between TDS under plant and in adjacent R. (d).

\section{Summary}

Treatment of industrial pollution is essential for improving environment and should be execute strictly. The domestic and agricultural pollution is difficult to collect, especially during heavy rainfall and flood. The riverletsmall lake net is the natural resource with various functions in history, but it becomes pollutants reservoir at present in many regions. The results reported in this paper may serve as one of the possible approaches with high cost performance for restoring the historical landscape.

\section{Acknowledgements}

The authors acknowledge the leadership of Hongshan district office for supporting this project and Dr. Xiaoyin Cheng, Jiangnan University, for her and her lab's help in chemical analysis during performance of this project.

\section{References}

[1] Pu, P.M., Hu, W.P., Pang, Y., Wei, Y.C., et al. (1993) A Physico-Ecological Enginering Experiment for Purifying Raw Water Quality in Lake. J. Lake Sciences, 5, 171-180.

[2] Pu, P.M., et al. (1993) Physic-Ecological Engineering for IMPROVING Taihu Lake water Quality in Intake Area of Mashan Drinking Water Plant. Proceedings of 5th International Conference on the Conservation and Management of Lakes, Stresa, 480-483.

[3] Hu, W.P. and Pu, P.M. (1995) Study on the Ecological Efficiency of Soft Enclosure in Lake Water. 6th International Conference on the Conservation and Management of Lakes-Kasmigaura'95, 1886-1889.

[4] Pu, P.M. (2011) The Role of Multifunctional Eco-Island Technic in Remediation for Healthy Aquaecosystem. Learning and Gathering of China. China Federation of Press, Beijing, 408-414.

[5] Li, Z.K. and Pu, P.M. China National Invitation Patent: ZL 200510038831.9 and ZL 200510038832.3.

[6] Pu, P.M. Application for China National Patent: No. 201110035542.9 and 201120048592.6.

[7] Liu, Z.K. (2010) Research on Oxydation of Root System of Wetland Plants and Its Impact on Removal of N, P Nu- 
trient in Dianchi. Thesis for Master Degree, Taiyuan Polytechnic University.

[8] Jaynes, M.L. and Carpenters, R. (1986) Effects of Vascular and Nonvascular Macrophytes on Sediment Redox and Solute Dynamics. Ecology, 67, 875-882. http://dx.doi.org/10.2307/1939810

[9] Li, G.H. and Liu, J.G. (2010) Root Oxygen Release and Heavy Metal Uptake of Various Wetland Plants. Water Resources Protection, 26.

[10] Shen, X.L., Hang, W.L., Hu, B., Zhou, M.W. and Sun S.R. (2009) Engineering Design for Second Face of Meicun Sewage Plant, Wuxi City, Jiangsu, China. Symposium on New Technics and New Technologies for Upgrade of Waterworks and Sewage Plant and Energy Conservation and Carbon Emission Reduction, 52-56. 